\title{
ALTERNATIF STRUKTUR ATAS JEMBATAN DENGAN GELAGAR BETON BERTULANG (Studi kasus: Peningkatan Jembatan Leuwi Putat, Kec. Pagelaran, Kab.Cianjur)
}

\author{
Yudi Sekaryadi, \\ Yayu Mustika \\ Program Studi Teknik Sipil \\ Fakultas Teknik Universitas Suryakancana
}

\begin{abstract}
ABSTRAK
Jembatan merupakan bangunan pelengkap jalan untuk memperlancar system transportasi darat dan sangat penting bagi manusia karena berfungsi sebagai penghubung antara satu daerah dengan daerah lainnya. Jembatan Leuwi Putat merupakan jembatan yang terletak di kecamatan Pagelaran, kabupaten Cianjur dan termasuk jembatan yang menunjang kelancaran perekonomian wilayah sekitar. Kondisi jembatan tersebut sudah tidak layak untuk dipakai jauh dari kata keamanan dan kenyamanan, untuk itu perlu diperbaiki dengan mendesain ulang struktur atas jembatan.

Pada tugas akhir ini dicoba mendesain struktur atas jembatan Leuwi Putatdengan jenis jembatan beton bertulang balok $T$ yaitu jembatan dengan jenis gelagar nya berbentuk huruf " $T$ " dengan bahan dasarnya dari beton dan baja. Panjang bentang jembatan 2 x 22 meter dengan lebar 5 meter. Peraturan untuk perancangan pembebanan struktur atas jembatan Leuwi Putat menggunakan peraturan Departemen Pekerjaan Umum. RSNI T-02-2005, untuk perancangan struktur beton menggunakan peraturanDepartemenPekerjaan Umum.RSNI T-04-2005, dan untuk rencana anggaran biaya menggunakan harga provinsi jawab barat tahun 2015 .

Hasil dari perhitungan konstruksi struktur atas jembatan didapat bahwa gelagar balok T didesain dengan tinggi 1,4 meter dan lebar 7 meter di butuhkan tulangan lentur 17 D32 dan sengkang D16 - 250, jembatan mampu menahan beban yang bekerja sepanjang 22 meter.Selain itu, dari hasil perhitungan trotoar, plat lantai jembatan dan balok diafragma yang dirancang untuk jembatan tersebut aman terhadap beban yang bekerja. Biaya yang dibutuhkan untuk mendasain ulang struktur atas jembatan leuwi putat yaitu sebesar Rp. $821,152,600.00$
\end{abstract}

Kata kunci :Jembatan, gelagar balok T, beton bertulang

\section{PENDAHULUAN}

Indonesia merupakan Negara dengan berbagai macam jenis kontur mulai dari pegunungan hingga dataran rendah serta sungai. Maka untuk memperlancar transportasi darat digunakan bangunan jembatan. Jembatan merupakan suatu struktur konstruksi yang menghubungakan dua bagian jalan yang terputus oleh adanya rintangan-rintangan seperti lembah, aliran sungai, selat dan rintangan lainnya.

Kondisi infrastruktur baik jalan dan jembatan di Wilayah Cianjur Selatan terlihat rusak berat, untuk itu Pemerintah Kabupaten Cianjur melalui Dinas Pekerjaan Umum melakukan perbaikan 
jembatan yang kondisinya memprihatinkan salah satunya peningkatan jembatan Leuwi Putat di Kecamatan Pagelaran. Upaya pemerintah untuk peningakatan jembatan Leuwi Putat tersebut adalah memperbaiki dan mendesain ulang struktur atas jembatan.

Penggunaan struktur beton bertulang merupakan salah satu alternatif peningkatan pada jembatan Leuwi Putat. Pelaksanaan jembatan beton bertulang bisa dilakukan tanpa perlu menggunakan alat berat, sehingga biaya pelaksanaan relative lebih murah. Jembatan beton bertulang cocok digunakan pada daerahdaerah dengan akses yang sulit dijangkau dimana kendaraan-kendaraan berat sulit mencapai lokasi proyek pembangunan jembatan, selain ini material penyusunan mudah diapatkan.

Masalah yang diteliti pada penelitian ini adalah bagaimana cara mendesain struktur atas jembatan Leuwi Putat dengan menggunakan gelagar beton bertulang.

Hasil dari penelitian ini diharapkan dapat menambah wawasan menganai perancangan struktur atas jembatan dengan beton bertulang sebagai bahan pertimbangan dalam menentukan desain alternative struktur atas jembatan yang sesuai dengan pertauran yang berlaku.

\section{METODOLOGI PENELITIAN}

Dalam bagan alir metodologi penelitian ini,terdiri dari:

1. Pengumpulan data

a. Data primer

b. Data sekunder

2. Perancangan Struktur Atas Jembatan
a. Pembebanan
b. Perancangan struktur
c. Kontrol kekuatan struktur

3. Gambar teknis dan Rencana Anggaran Biaya

4. HASIL DAN PEMBAHASAN
$\begin{array}{ll}\text { Data Teknis Jembatan } \\ \text { Jenis pembebanan } & =\text { BM } 100 \% \\ \text { Panjang bentang } & =22 \times 2 \text { meter } \\ \text { Lebar trotoar } & =1 \text { meter } \\ \text { Lebar total jembatan } & =7 \text { meter } \\ \text { Tebal slab } & =0,20 \text { meter } \\ \text { Jarak gelagar } & =1,40 \text { meter }\end{array}$

Dimensi gelagar :

$$
\begin{array}{ll}
\text { Lebar } & =0,50 \text { meter } \\
\text { Tinggi } & =1,40 \text { meter }
\end{array}
$$

a. Perhitungan Tiang sandaran

Berdasarkan RSNI-02-2005 Faktor beban ultimit untuk beban trotoar

yaitu, $\mathrm{K}_{\mathrm{Tp}}=1,8$

Jarak antara tiang sandaran

$\mathrm{L}=2,00 \mathrm{~m}$.

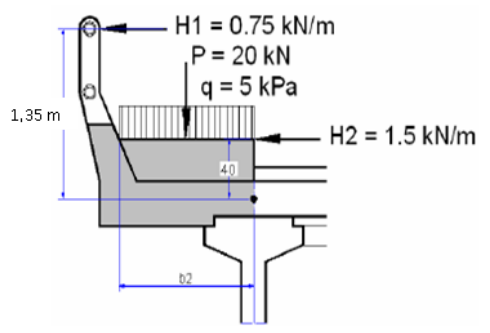

Berdasarkan gambar diatas gaya horisontal pada tiang sandaran yaitu $\mathrm{H} 1 \times \mathrm{L}$ didapat 1,50 $\mathrm{kN}$

Momen dan gaya geser pada tiang sandaran :

$\mathrm{Mu}=1,8 \times 1,50 \times 1,35=3,65 \mathrm{kNm}$

$\mathrm{Vu}=1,8 \times 1,50 \times 1,35=3,65 \mathrm{kN}$

Berdasarkan hasil perhitungan penulangan dengan memakai mutu beton K-175 dan mutu baja U 24, didapat tulangan lentur $4 \varnothing 10$ dan tulangan sengkang $\emptyset 8-200 \mathrm{~mm}$.

\section{b. Perhitungan Slab trotoar}

\begin{tabular}{|c|c|c|c|c|c|c|c|}
\hline Bidang & h (m) & b (m) & $\mathrm{L}(\mathrm{m})$ & $\begin{array}{c}\text { Berat } \\
\text { Beton } \\
(\mathrm{KN} / \mathrm{m})\end{array}$ & $\begin{array}{c}\text { Berat } \\
(\mathrm{KV})\end{array}$ & $\begin{array}{l}\text { Lengan } \\
\text { (m) }\end{array}$ & $\begin{array}{l}\text { Momen } \\
(\mathrm{KN} / \mathrm{m})\end{array}$ \\
\hline 1 & 0,25 & 0,70 & 2,00 & 25,00 & 8,750 & 0,350 & 3,063 \\
\hline 2 & 0,25 & 0,07 & 2,00 & 25,00 & 0,875 & 0,723 & 0,633 \\
\hline 3 & 0,45 & 0,19 & 0,15 & 25,00 & 0,321 & 0,537 & 0,172 \\
\hline 4 & 0,45 & 0,10 & 0,15 & 25,00 & 0,084 & 0,720 & 0,061 \\
\hline 5 & 0,45 & 0,10 & 0,15 & 25,00 & 0,169 & 0,803 & 0,136 \\
\hline 6 & 0,55 & 0,20 & 0,15 & 25,00 & 0,413 & 0,770 & 0,318 \\
\hline 7 & 0,20 & 0,70 & 2,00 & 25,00 & 7,000 & 0,350 & 2,450 \\
\hline 8 & \multicolumn{2}{|c|}{ Besi galvanis } & 4 & & 2,520 & 1,000 & 2,520 \\
\hline \multicolumn{5}{|c|}{ TOTAL } & 20,131 & & 9,351 \\
\hline
\end{tabular}

Tabel 4.1 perhitungan berat sendiri dan momen

Momen trotoar per meter lebar

$\mathrm{Mms}=9,351 / 2=4,676 \mathrm{kNm}$

Tabel 4.2 Perhitungan Beban Hidup

\begin{tabular}{|c|l|r|r|r|}
\hline $\mathbf{N}_{\mathbf{0}}$ & \multicolumn{1}{|c|}{ Jenis bahan } & Gaya (KN) & Lengan (m) & $\begin{array}{r}\text { Momen } \\
(\mathbf{K N m})\end{array}$ \\
\hline 1 & Beban horisontal pada railling $(\mathrm{H} 1)$ & 0,750 & 1,35 & 1,013 \\
\hline 2 & Beban horisonta pada kerb $(\mathrm{H} 2)$ & 1,5 & 0,35 & 0,525 \\
\hline 3 & Beban vertikal terpusat $(\mathrm{P})$ & 20 & 0,35 & 7,00 \\
\hline 4 & Beban vertikal merata = $\mathrm{q}^{*} \mathrm{~b} 2$ & 3,50 & 0,35 & 1,225 \\
\hline \multicolumn{3}{|c|}{ Total $\mathbf{M}_{\text {TP }}$} & & 9,763 \\
\hline
\end{tabular}

faktor beban ultimit berat sendiri $=1,3$ faktor beban ultimit beban hidup $=1,8$ Maka momen ultimit slab trotoar : 


$$
\begin{aligned}
\mathrm{Mu} & =(1,3 \times 4,678)+(1,8 \times 9,763) \\
& =25,188 \mathrm{kNm}
\end{aligned}
$$

Berdasarkan hasil perhitungan penulangan dengan memakai mutu beton K-250 dan mutu baja U 24, didapat tulangan lentur $\emptyset 16-150$ $\mathrm{mm}$ dan tulangan bagi $\varnothing 12-200 \mathrm{~mm}$.

\section{c. Perhitungan Plat kendaraan}

Berat akibat beban tetap $=11,88 \mathrm{kN} / \mathrm{m}^{2}$ Momen akibat beban tetap :

$$
\begin{aligned}
\mathrm{M} & =1 / 10 \mathrm{q} \mathrm{L}^{2} \\
& =1 / 10 \times 11,88 \times 1,4^{2} \\
& =2,328 \mathrm{kNm}
\end{aligned}
$$

Berat akibat beban hidup " $\mathrm{T}$ "

Berat beban $\mathrm{T}$ sebesar $100 \mathrm{kN}$. Untuk menghitung momen terbagi menjadi 2 kondisi, dimana roda berada di tengah pelat dan dua roda berdekatan. Momen yang terbesar akibat kondisi roda berada di tengah pelat, yaitu :

$\mathrm{M}_{\mathrm{xm}}=30,677 \mathrm{kNm}$

$\mathrm{M}_{\mathrm{ym}}=16,801 \mathrm{kNm}$

Maka total momen pada pelat akibat beban mati dan beban hidup :

$$
\begin{aligned}
\mathrm{M}_{\mathrm{x}} & =\mathrm{M}_{\mathrm{xDL}}+\mathrm{M}_{\mathrm{xLL}} \\
& =30,677+2,328 \\
& =33,005 \mathrm{kNm} \\
\mathrm{M}_{\mathrm{y}} & =\mathrm{M}_{\mathrm{yDL}}+\mathrm{M}_{\mathrm{yLL}} \\
& =16,801+2,328 \\
& =19,129 \mathrm{kNm}
\end{aligned}
$$

Berdasarkan hasil perhitungan penulangan dengan memakai mutu beton K-350 dan mutu baja U 39, didapat tulangan arah x D16 - 250 $\mathrm{mm}$ dan tulangan arah y D $12-250 \mathrm{~mm}$.

\section{d. Perhitungan Pelat injak}

Berat sendiri pelat injak sebesar $=61,248$ $\mathrm{kN} / \mathrm{m}$

Beban terpusat $(\mathrm{P})=100 \mathrm{kN}($ Tekanan roda $)$

Momen pelat injak :

$\mathrm{M}=1 / 8 \mathrm{ql}^{2}+1 / 4 \mathrm{PL}$

$$
=\left(1 / 8 \times 61,248 \times 3^{2}\right)+(1 / 4 \times 10 \times 3)
$$

$$
=76,404 \mathrm{kNm}
$$

Berdasarkan hasil perhitungan penulangan dengan memakai mutu beton K-350 dan mutu baja U 39, didapat tulangan D16 - $100 \mathrm{~mm}$ dan tulangan bagi D 12 - $250 \mathrm{~mm}$.

\section{e. Perhitungan Gelagar balok T}

Pembebanan gelagar balok $\mathrm{T}$ terdiri dari :

\begin{tabular}{|c|c|c|c|c|c|c|}
\hline \multirow{2}{*}{ No } & \multirow[b]{2}{*}{ Jenis Beban } & \multirow{2}{*}{$\begin{array}{l}\text { Faktor } \\
\text { Beban }\end{array}$} & \multirow[b]{2}{*}{$\mathrm{M}(\mathrm{kNm})$} & Komb-1 & Komb-2 & Komb-3 \\
\hline & & & & $\begin{array}{c}\mathrm{Mu} \\
(\mathrm{kNm})\end{array}$ & $\begin{array}{c}\mathrm{Mu} \\
(\mathrm{kNm})\end{array}$ & $\begin{array}{c}\mathrm{Mu} \\
(\mathrm{kNm})\end{array}$ \\
\hline 1 & Berat sendiri (MS) & 1.30 & 1411.83 & 1835.38 & 1835.38 & 1835.38 \\
\hline 2 & $\begin{array}{l}\text { Beban mati tambahan } \\
\text { (MA) }\end{array}$ & 2.00 & 340,98 & 681,96 & 681,96 & 681,96 \\
\hline 3 & \begin{tabular}{|l} 
Beban lajur "D" \\
(TD/TT)
\end{tabular} & 1.80 & 1295.00 & 2331.00 & 2331.00 & 2331.00 \\
\hline 4 & Gaya rem (TB) & 1.80 & 20.48 & 36,86 & 36,86 & \\
\hline 5 & Beban angin (EW) & 1.20 & 44.90 & 53,88 & & \\
\hline 7 & Beban gempa (EQ) & 1.00 & 301,53 & & & 301,53 \\
\hline & Total Kombinasi Mome & ultimit & $\mathrm{Mu})$ & 4939,08 & 4885,2 & 5149,9 \\
\hline
\end{tabular}

$$
\text { Beban sendiri } \quad=23,336 \mathrm{kN} / \mathrm{m}
$$

\begin{tabular}{|c|c|c|c|c|c|c|}
\hline & \multirow[b]{2}{*}{ Jenis Beban } & \multirow[b]{2}{*}{$\begin{array}{l}\text { Faktor } \\
\text { Beban }\end{array}$} & \multirow[b]{2}{*}{$\mathrm{M}(\mathrm{kNm})$} & Komb-1 & Komb-2 & Komb-3 \\
\hline No & & & & $\begin{array}{c}\mathrm{Mu} \\
(\mathrm{kNm})\end{array}$ & $\begin{array}{c}\mathrm{Mu} \\
(\mathrm{kNm})\end{array}$ & $\begin{array}{c}\mathrm{Mu} \\
(\mathrm{kNm})\end{array}$ \\
\hline 1 & Berat sendiri (MS) & 1.30 & 470,60 & 611,78 & 611,78 & 611,78 \\
\hline 2 & $\begin{array}{l}\text { Beban mati tambahan } \\
\text { (MA) }\end{array}$ & 2.00 & 113,66 & 227,32 & 227,32 & 227,32 \\
\hline 3 & $\begin{array}{l}\text { Beban lajur "D" } \\
\text { (TD/TT) }\end{array}$ & & 1295.00 & 2331.00 & 2331.00 & 2331.00 \\
\hline 4 & Gaya rem (TB) & 1.80 & 22.48 & 36,86 & 36,86 & \\
\hline 5 & Beban angin $(\mathrm{El}$ & 1.2 & 14,93 & 17,92 & & \\
\hline 7 & Beban gempa (EQ) & 1.00 & 100,51 & & & 100,51 \\
\hline & Total Kombinasi Mo & uttim & (u) & 3224.88 & 3207 & 3270,61 \\
\hline
\end{tabular}$$
\text { Beban tambahan } \quad=5,636 \mathrm{kN} / \mathrm{m}
$$

Beban lalin D/T $=140 \mathrm{kN}$

\begin{tabular}{|c|c|c|c|c|c|c|}
\hline \multirow{2}{*}{ No } & \multirow[b]{2}{*}{ Jenis Beban } & \multirow[b]{2}{*}{$\begin{array}{l}\text { Faktor } \\
\text { Beban }\end{array}$} & \multirow[b]{2}{*}{$\mathrm{V}(\mathrm{kN})$} & Komb-1 & Komb-2 & Komb-3 \\
\hline & & & & $\mathrm{Vu}(\mathrm{kN})$ & $\mathrm{Vu}(\mathrm{kN})$ & $\mathrm{Vu}(\mathrm{kN})$ \\
\hline 1 & Berat sendiri (MS) & 1.30 & 256.70 & 333.71 & 333.71 & 333.71 \\
\hline 2 & $\begin{array}{l}\text { Beban mati } \\
\text { tambahan (MA) }\end{array}$ & 2.00 & 61,99 & 123,98 & 123,98 & 123,98 \\
\hline 3 & $\begin{array}{l}\text { Beban lajur "D" } \\
\text { (TD/TT) }\end{array}$ & 1.80 & 181.36 & 326.45 & 326.45 & 326.45 \\
\hline 4 & Gaya rem (TB) & 1.80 & 1,86 & 3,35 & 3,35 & \\
\hline 5 & Beban angin (EW) & 1.20 & 8.15 & 9.78 & & \\
\hline 6 & Beban gempa (EQ) & 1.00 & 54,82 & & & 54,82 \\
\hline & ttal kombinasi gaya & ser ultin & $(\mathrm{Vu})$ & 797,27 & 787,19 & 838,9 \\
\hline
\end{tabular}

$$
\begin{array}{ll}
\text { Beban akibat rem } & =15,75 \mathrm{kN} \\
\text { Beban angin } & =0,7405 \mathrm{kN} / \mathrm{m}
\end{array}
$$

Beban gempa horisontal $=4,984 \mathrm{kN} / \mathrm{m}$ rumus momen yang digunakan :

$1 / 8 \mathrm{q} \mathrm{L}^{2} \rightarrow$ momen lapangan

$1 / 12 \mathrm{qL}^{2} \rightarrow$ momen tumpuan (kanan kiri)

Momen yang dikalikan dengan faktor beban ultimit berdasarkan RSNI T-02-2005, kemudian di kombinasikan.

Table 4.3 Kombinasi Momen ultimit lapangan

Table 4.4 Kombinasi Momen ultimit tumpuan

Tabel 4.5 Kombinasi gaya geser ultimit

Dari kombinasi beban beban, maka Momen ultimit dan gaya geser ultimit terbesar terjadi pada kombinasi 3 dimana beban gaya rem dan beban angin diabaikan.

Mul $=5149,9 \mathrm{kNm}$

Mut $=3270,61 \mathrm{kNm}$

$\mathrm{Vu}=838,9 \mathrm{kN}$

Untuk menganalisis balok T pada jembatan ini, perhitungan yang dilakukan sama seperti pada balok persegi karena garis netral balok $\mathrm{T}$ berada pada sayap balok .

Berdasarkan hasil perhitungan penulangan dengan memakai mutu beton K-350 dan mutu baja U 39, digunakan tulangan lapangan 17 D32, tulangan tumpuan 11 D32 dan tulangan sengkang D16-250 mm. 


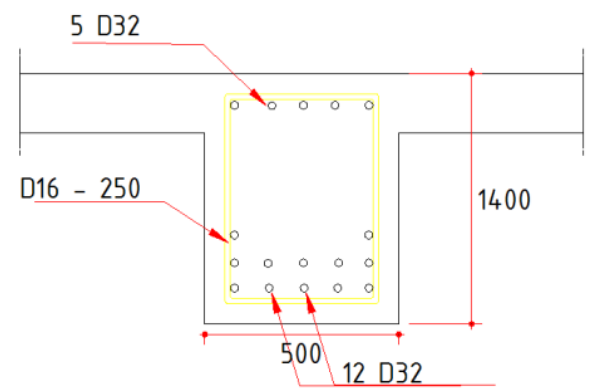

Gambar 4.2 Detail tulangan lapangan balok T

\section{f. Perhitungan Lendutan gelagar}

berdasarkan SNI 2002, rumus lendutan adalah

$$
\delta \quad=\frac{\frac{5}{384} \times Q \times L^{4}}{(E c \times l e)}
$$

dimana lendutan terjadi akibat beban - beban yang bekerja pada gelagar jembatan.

Kemudian di cari lendutan maksimum pada balok dengan rumus :

$$
\begin{aligned}
\delta_{\text {maks }} & =\mathrm{L} / 240 \\
& =22,00 / 240 \\
& =0,09167 \mathrm{~m}
\end{aligned}
$$

Tabel 4.6 Kombinasi lendutan

\begin{tabular}{|c|l|r|r|r|}
\hline No. & \multicolumn{1}{|c|}{ Jenis Beban } & $\begin{array}{c}\text { Komb-1 } \\
(\mathrm{kNm})\end{array}$ & $\begin{array}{c}\text { Komb-2 } \\
(\mathrm{kNm})\end{array}$ & $\begin{array}{c}\text { Komb-3 } \\
(\mathrm{kNm})\end{array}$ \\
\hline 1 & Berat sendiri(MS) & 0.0204 & 0.0204 & 0.0204 \\
\hline 2 & Beban mati tambahan(MA) & 0.0049 & 0.0049 & 0.0049 \\
\hline 3 & Beban lajur "D"(TD/TT) & 0.0159 & 0.0159 & 0.0159 \\
\hline 4 & Gaya rem(TB) & 0.0002 & 0.0002 & \\
\hline 5 & Beban angin(EW) & 0.0006 & & \\
\hline 7 & Beban gempa(EQ) & & & 0.0044 \\
\hline \multicolumn{2}{|c|}{ Total } & $\mathbf{0 . 0 4 2 1}$ & $\mathbf{0 . 0 4 1 5}$ & $\mathbf{0 . 0 4 5 7}$ \\
\hline
\end{tabular}

Maka: Lendutan kombinasi 1

$0,0421<\mathrm{L} / 240 \ldots$. OK

Lendutan kombinasi 2

$0,0415<\mathrm{L} / 240 \ldots$. OK

Lendutan kombinasi 3

$0,0457<\mathrm{L} / 240 \ldots$. OK

\section{g. Rencana Anggaran Biaya}

\begin{tabular}{|c|l|c}
\hline $\begin{array}{c}\text { No. } \\
\text { DIVISI }\end{array}$ & \multicolumn{1}{|c|}{ URAIAN } & $\begin{array}{c}\text { Jumlah Harga } \\
\text { Pekerjaan } \\
\text { (Rp) }\end{array}$ \\
\hline 1 & UMUM & $11,960,000.00$ \\
\hline 7 & STRUKTUR & $734,542,330.45$ \\
\hline (A) & $\begin{array}{l}\text { Jumlah Harga Pekerjaan (termasukBiaya } \\
\text { Umum dan Keuntungan) }\end{array}$ & $746,502,330.45$ \\
\hline (B ) & Pajak Pertambahan Nilai(PPn) = 10\% (A) & $74,650,233.04$ \\
\hline (C) & Jumlah Total Harga Pekerjaan = (A)+(B) & $821,152,600.00$ \\
\hline Terbilang: & $\begin{array}{l}\text { DELAPANRATUSDUAPULUHSATUJTA SERATUSLIMA PULUH } \\
\text { DUA RIBUENAMRATUSRUPLAH }\end{array}$ \\
\hline
\end{tabular}

Rencana anggaran biaya untuk struktur atas jembatan Leuwi Putat senilai Rp.

$821,152,600.00$.

\section{KESIMPULAN DAN SARAN}

\section{A. Kesimpulan}

Berdasarkan hasil perhitungan konstruksi

dapat disimpulkan bahwa :

Bahan struktur yang digunakan :

a. Mutu beton K-175 untuk tiang sandaran dengan mutu baja $U 24$ polos

b. Mutu beton K-250 untuk slab trotoar dengan mutu baja $U 24$ polos

c. Mutu beton K-350 untuk pelat kendaraan, pelat injak, gelagar dan balok diafragma dengan mutu baja U 39 ulir.

Hasil dari perhitungan tulangan yang diperlukan adalah sebagai berikut:
a. Tiang sandaran
Lentur $\quad: 4 \emptyset 10$
Sengkang : $\varnothing 8-200 \mathrm{~mm}$
b. Slab trotoar

$\begin{array}{ll}\text { Lentur } & : \varnothing 16-150 \mathrm{~mm} \\ \text { Bagi } & : \varnothing 12-200 \mathrm{~mm}\end{array}$

c. Pelat lantai kendaraan

Tul. Arah x : $\emptyset 16-250 \mathrm{~mm}$

Tul. Arah y : $\emptyset 16-250 \mathrm{~mm}$
d. Pelat injak
Lentur : $\emptyset 16-100 \mathrm{~mm}$
Bagi $\quad: \emptyset 12-250 \mathrm{~mm}$
e. Gelagar Balok T
Tul. Lapangan : 17 D32
Tul. Tumpuan : 11 D32
Tul. Sengkang $\quad: \varnothing 16-250 \mathrm{~mm}$

Hasil kontrol kekuatan momen dari semua struktur atas jembatan dengan tulangan yang direncanakan bahwa

momen rencana $>$ Momen ultimit yang artinya dimensi struktur yang direncanakan aman terhadap beban- beban yang bekerja di sepanjang bentang. Dan lendutan yang terjadi pada gelagar akibat beban yang bekerja lebih kecil dari lendutan maksimum.

\section{B. Saran}

Berdasarkan hasil perancangan struktur atas jembatan Leuwi Putat maka terkait beberapa saran yang berkaitan dengan perencanaan yaitu:

a. Perlu dicoba menggunakan profil gelagar yang lebih ekonomis.

b. Dalam mengasumsikan beban-beban yang bekerja pada jembatan harus diperhitungkan lebih teliti. 
c. Setelah didapat hasil perhitungan perlu dilakukan review design untuk memastikan jembatan aman atau tidak.

\section{DAFTAR PUSTAKA}

Asiyanto, 2008. Metode Konstruksi Jembatan beton, UI Press, Jakarta

Departemen Pekerjaan Umum, 2005. RSNI T-02-2005: Standar Pembebanan Untuk Jembatan. Badan Litbang PU.

Departemen Pekerjaan Umum, 2005. RSNI T-04-2005: Perencanaan Struktur Beton Untuk Jembatan. Badan Litbang PU.

Hariandja, Binsar. 1986. Disain Beton Bertulang Edisi Keempat. Jakarta: Erlangga.

Materi perkuliahan Universitas Suryakancana Jurusan Teknik Sipil: Struktur Jembatan oleh Yudi Sekaryadi., Ir, MT. 2016

Materi Perkuliahan Universitas Suryakancana Jurusan Teknik Sipil: Struktur Beton II oleh Yudi Sekaryadi., Ir, MT. 2016

Supriyadi, Bambang \& Muntohar, Agus Setyo. 2007. Jembatan Edisi Pertama. Yogyakarta: Beta Offset. 
